\title{
Устройство слежения за Солнцем в фотоэлектрических энергетических установках
}

\author{
О. Пчельникова-Гротова, к. т. н. ${ }^{1}$, А. Иванов ${ }^{2}$ В. Латыпов ${ }^{3}$
}

УДК 620.4:621.311.25:62-52 | ВАК 05.11.07

\begin{abstract}
В первой статье авторского коллектива по данной тематике [1] был рассмотрен порядок расчета автономных фотоэлектрических энергетических установок, не привязанный к количеству солнечной энергии, падающей на солнечные панели; для справки были приведены источники, содержащие данные по количеству солнечного излучения, падающего на горизонтальную приемную площадку определенного размера в разных районах мира. Однако понятно, что фиксированное горизонтальное расположение панелей существенно ограничивает потенциал солнечной энергетической установки (СЭУ); обеспечив ориентацию панелей в направлении на Солнце, можно получить до 50\% повышения эффективности ее работы. В данной статье приведено описание системы слежения за Солнцем для СэУ, разрабатываемой коллективом специалистов Московского авиационного университета.
\end{abstract}

дним из главных критериев, по которому оцениваются эффективность и уровень производительности СЭУ, является КПД солнечных панелей. Повысить этот показатель можно несколькими способами. Можно применять многослойные панели, состоящие из набора материалов, расположенных так, чтобы улавливались кванты всех спектров солнечного излучения". Но такие материалы слишком дороги для стационарных станций гражданского и общетехнического назначения. Использование различного вида концентраторов в виде линз, фоконов или фоклинов сопровождается повышением температуры панелей, что снижает их КПД, и для возвращения его к номинальным значениям требуется введение устройств принудительного охлаждения. Поэтому наиболее эффективным является применение систем непрерывного слежения за Солнцем, обеспечивающих существенное увеличение вырабатываемой мощности (на 20-60\%, в зависимости от того, в какой точке мира установлена солнечная электростанция) и более равномерное генерирование электроэнергии в течение дня (рис. 1) [2, 3].

МАИ (НИУ), доцент, grotova@mail.ru.

МАИ (НИУ), магистр, aleksey.ivanov.1995@mail.ru.

МАИ (НИУ), магистр, tapor27.1994@mail.ru.

Например, компанией Sharp разработаны трехслойные фотоэлементы, состоящие из слоев фосфида индия-галлия, арсенида галлия и арсенида индия-галлия, разделенных диэлектриком, служащим для получения туннельного эффекта. КПД таких элементов составляет $44 \%$.
В течение дня выработка энергии солнечными панелями падает на 10\% и более из-за их нагрева [1]. Поэтому очень важно увеличить выработку панелей в утренние часы, что наилучшим образом выполняется при помощи следящей системы. Дополнительным преимуществом, существенным для нашего климата, является отсутствие необходимости очищать панели от снега в зимний период, так как значительную часть времени они находятся в положении, близком к вертикальному. Использование следящих устройств позволяет при равной мощности

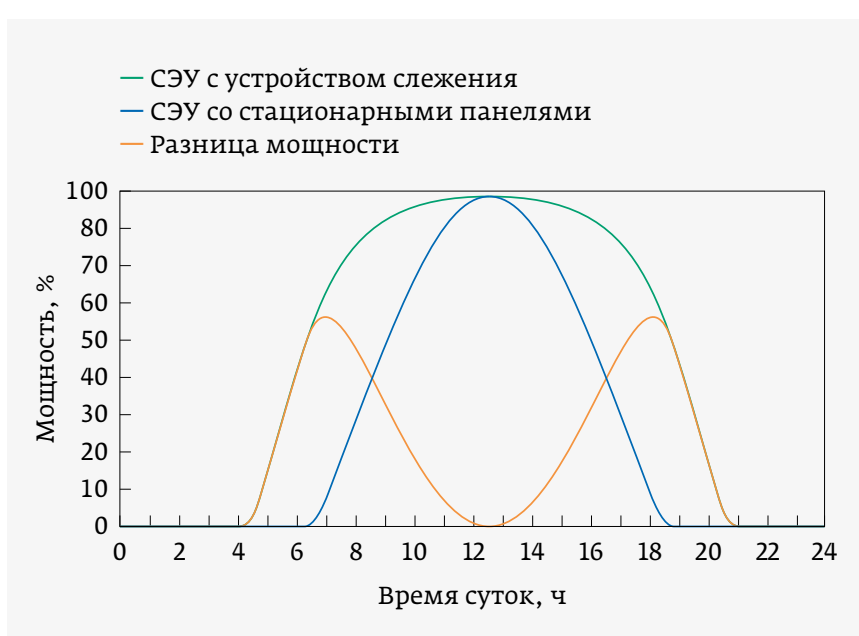

Рис. 1. Суточный график мощности СэУ в летний день (данные для трекера ТСВ-3500 производства компании ГК РосПромМаш [4]) 


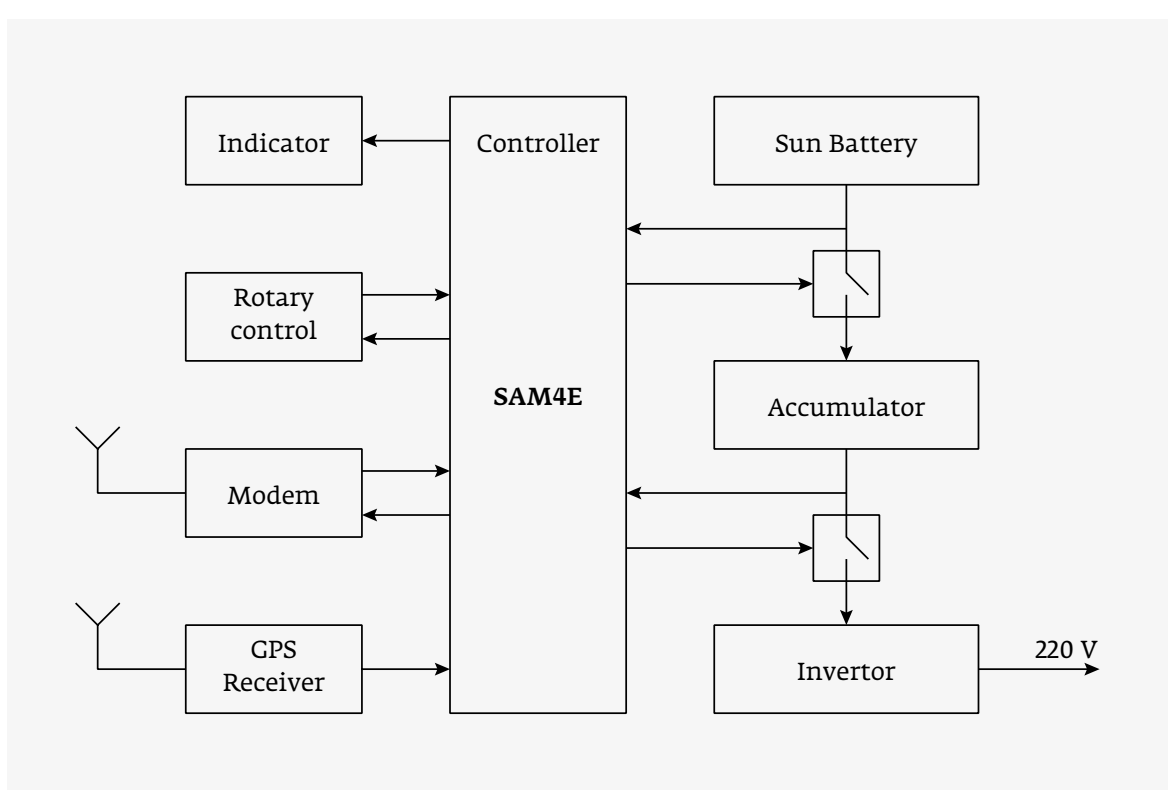

Рис. 2. Схема взаимодействия контроллера с приборами и агрегатами солнечной станции

уменьшить габаритные размеры СЭУ и сэкономить площадь земельного участка.

Коллективом авторов Московского авиационного университета разрабатывается система слежения за Солнцем, состоящая из поворотного механизма и блока управления. Поворотный механизм состоит из гидроцилиндров, гидронасоса, системы циркуляции жидкости, преобразователя линейного движения штоков гидроцилиндров в угловое перемещение панелей и двух электромагнитов, фиксирующих положение осей вращения панелей.

Включение насоса подачи гидравлической жидкости и управление направлением движения гидравлического механизма выполняется по командам, поступающим с блока управления. Логика выполнения основных функций блока управления реализована в контроллере, который получает информацию от ряда датчиков и каналов связи и выдает команды на исполнительные устройства. Помимо аппаратуры и программ, необходимых для выполнения основной задачи, контроллер содержит также схемы защиты аккумуляторной батареи от превышения допустимого уровня зарядки и отключения инвертора (нагрузки) при неприемлемом снижении напряжения на его входе. В составе блока управления имеются средства для отображения информации о текущей ориентации панелей и модем для передачи диагностических данных и приема команд в виде SMS на телефон пользователя или по электронной почте (SMTP) - в зависимости от настройки модема.

Связи контроллера с другими устройствами блока управления и агрегатами солнечной энергетической установки схематически показаны на рис. 2. Можно видеть, что контроллер (Controller) получает сигналы точного времени и географических координат объекта с приемника (GPS receiver), формирует команды для силовых цепей управления поворотным механизмом и получает сигналы обратной связи по положению панелей (Rotary control), передает и принимает информацию от модема (Modem), управляет отключением/подключением аккумуляторной батареи (Accumulator) и инвертора (Invertor). Информация о режиме работы устройства выдается на светодиодную панель (Indicator).

Разработанный контроллер позволяет управлять поворотом фотоэлектрических панелей в двух режимах. В облачную погоду панели поворачиваются через равные промежутки времени на углы, рассчитанные по программе, введенной в память $\mathrm{KoH}^{-}$ троллера. В ясную погоду панели непрерывно разворачиваются в направлении Солнца в соответствии с информацией, полученной от фотодатчиков; точность их ориентации в этом случае выше, чем в программном режиме.

Для постоянной ориентации панелей перпендикулярно к потоку солнечных лучей необходимо изменять их положение в двух плоскостях, учитывая вращение Земли вокруг Солнца и вокруг своей оси [5]. В горизонтальной системе координат (рис. 3) в зависимости от широты местности ( $\varphi$ ) определяются высота солнцестояния $h$ (угол между направлением на Солнце и горизонтальной плоскостью) и азимут А (угол между плоскостью меридиана и вертикальной плоскостью). В экваториальной системе координат (рис. 4) в соответствии со временем суток рассчитываются склонение светила $\delta$ (угол между направлением на Солнце и экваториальной плоскостью) и часовой угол $\tau$ (угловое смещение Солнца от полудня).

Угловые параметры расположения Солнца рассчитываются по формулам [6, 7]

$$
\begin{gathered}
\delta=23,45 \sin \left[\frac{360}{365}(n-81)\right], \\
\tau=15^{\circ} \cdot\left(T_{c}-12\right), \\
h=\arccos (\sin \delta \cdot \sin \varphi+\cos \delta \cdot \cos \tau \cdot \cos \varphi), \\
A=\arcsin \left(\cos \delta \cdot \frac{\sin \tau}{\cos h}\right),
\end{gathered}
$$

где $n$ - порядковый номер дня года,

$\mathrm{T}_{c}$ - местное солнечное время. 


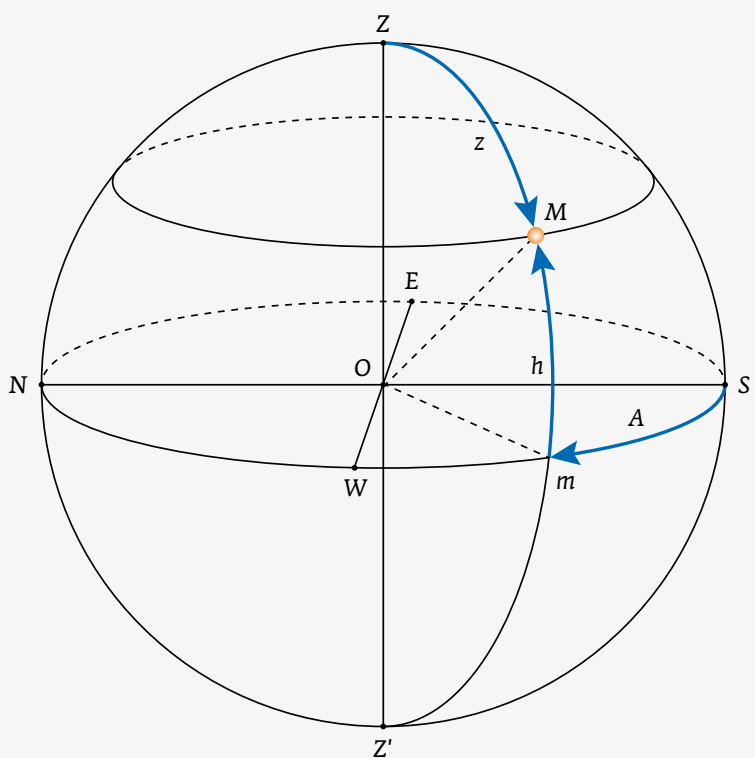

Рис. 3. Горизонтальная система координат: $h$ - высота светила $M$ над горизонтом; z - зенитное расстояние; $A$ - азимут

Приведенные формулы лежат в основе заложенной в память контроллера программы, которая через определенные интервалы времени по полученным приемником GPS географической широте местности, местному времени и дате рассчитывает высоту $h$ и азимут A Солнца. После этого исполнительные устройства переориентируют фотоэлектрические панели в расчетное положение, в котором они фиксируются до следующего цикла управления.

В таком режиме система слежения работает в облачную погоду. Для организации обратной связи по углу поворота в конструкцию поворотного устройства введены пружины, закрепленные параллельно со штоками гидроцилиндров. Сила растяжения этих пружин, пропорциональная углу поворота панелей, измеряется тензометрическими датчиками силы EMS20 фирмы EMSYST [8]. По сравнению с датчиками других типов, которыми можно измерять угол поворота, EMS20 имеет невысокую цену и сравнительно просто устанавливается в конструкцию поворотного механизма.

Во втором режиме система слежения начинает работать при поступлении через модем команды «Солнечный день». В этом случае для точного наведения панелей на солнце используется механически связанная с ними сборка из двух расположенных под углом друг к другу фотодатчиков (рис. 5). Роль последних выполняют фоторезисторы на основе сульфида кадмия - ФСК-Г7, изменяющие величину сопротивления при облучении светом. Система регулирования

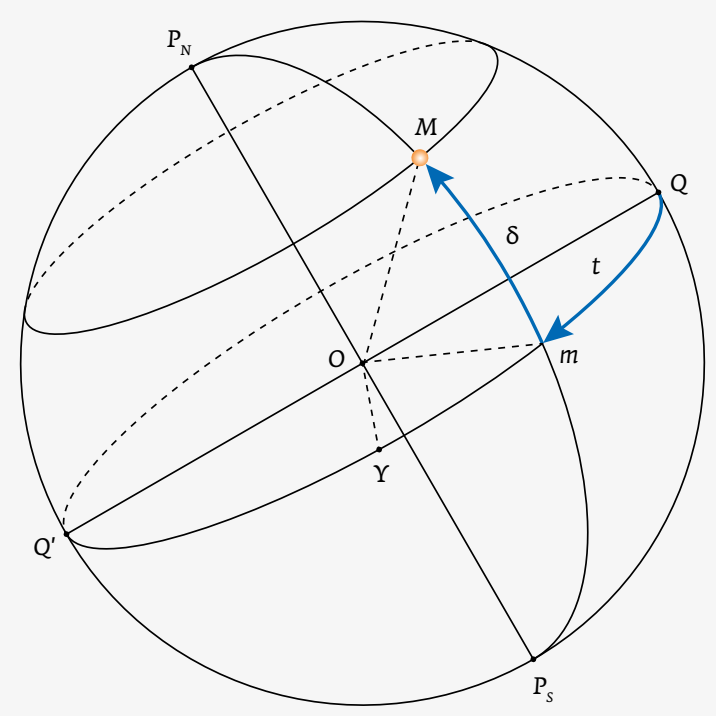

Рис. 4. Экваториальная система координат: $\delta$ - склонение светила $M ; \tau$ - часовой угол

поворачивает панели до выравнивания уровней сигналов от этих датчиков.

При отсутствии сигнала рассогласования с фотодатчиков и остановке механизма на определенный период времени программа принимает решение о наличии облачности и начинает работать по алгоритму первого режима: рассчитывается текущее значение требуемого положения панелей в соответствии со временем суток, и механизм поворачивает панели в правильном направлении.

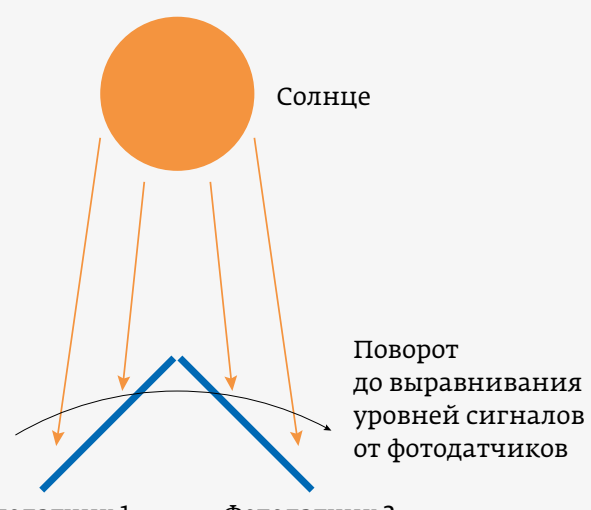

Фотодатчик 1 Фотодатчик 2

Рис. 5. Принцип управления положением панелей по разности сигналов фотодатчиков 


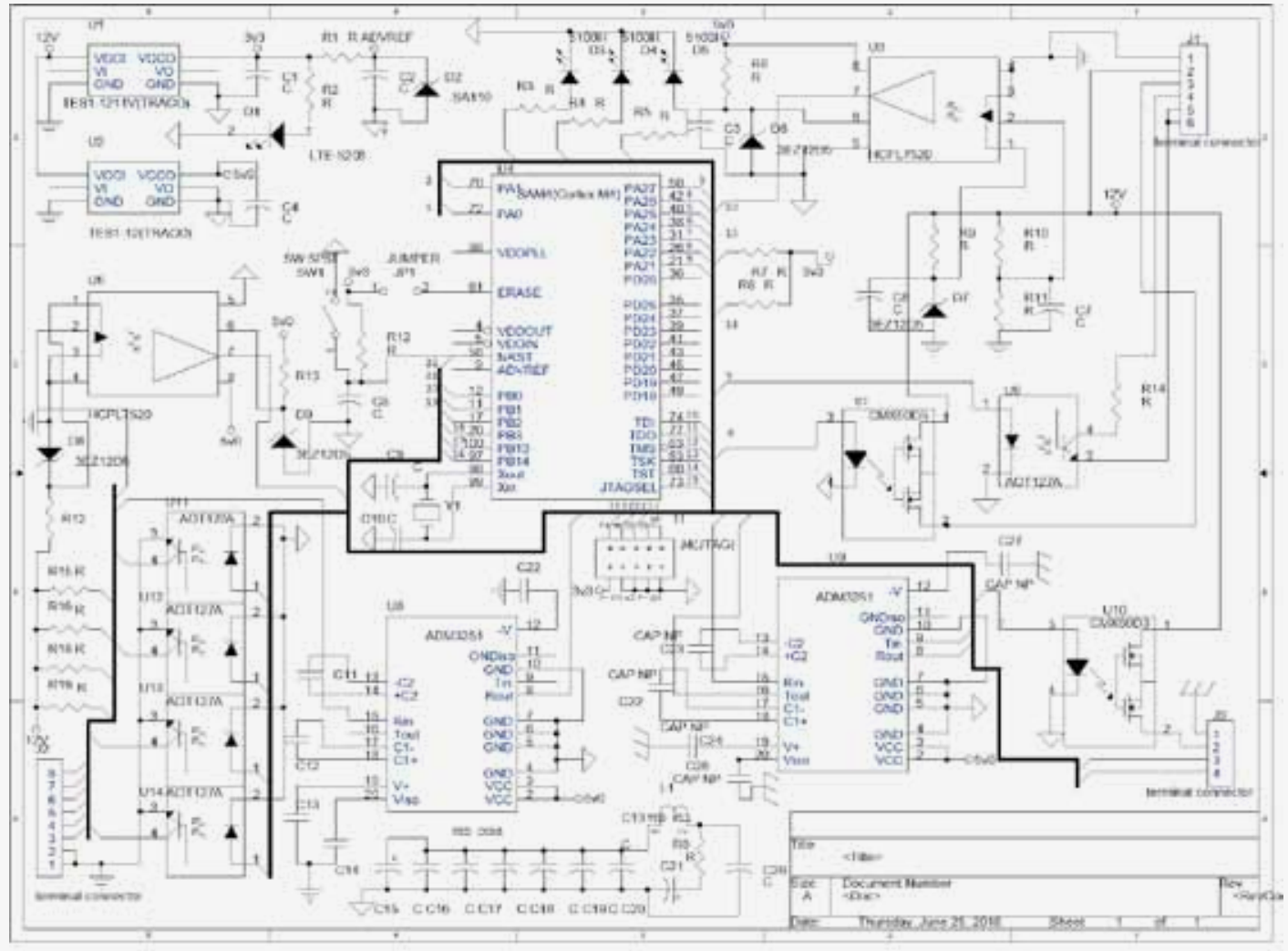

Рис. 6.

Электрическая схема контроллера блока управления
Основным управляющим элементом контроллера является быстродействующий 16-разрядный микроконтроллер SAM4E (Cortex M4 Atmel) [9]. Электрическая схема контроллера приведена на рис. 6.

Таблица 1. Назначение микросхем контроллера

\begin{tabular}{ll} 
Mикросхема & Назначение \\
U1, U2 & Обеспечение гальванически развязанного питания платы \\
\hline U3 & $\begin{array}{l}\text { Гальваническая развязка аналогового сигнала «Уровень заряда аккумулятора" и входа АЦП } \\
\text { микроконтроллера }\end{array}$ \\
\hline U4 & Микроконтроллер SAM4E \\
\hline U5 & Отключение солнечной батареи от аккумулятора \\
\hline U6 & Отключение инвертора от аккумулятора \\
\hline U8 & Гальваническая развязка аналогового сигнала с фотодатчиков и входа АЦП микроконтроллера \\
\hline U9 & Приведение уровня сигнала с приемника СРS к уровню сигналов на входе микроконтроллера \\
\hline U10 & Подключение питания к модему перед передачей информации \\
\hline U11, U12 & Управление электромагнитами, фиксирующими оси поворота батареи \\
\hline U13, U14 & $\begin{array}{l}\text { Включение насоса подачи гидравлической жидкости и управление направлением движения } \\
\text { гидравлического механизма }\end{array}$ \\
\hline
\end{tabular}


Таблица 2. Назначение разъемов контроллера

\begin{tabular}{ll} 
Разъем & Подсоединяемые устройства \\
J1 & $\begin{array}{l}\text { Солнечная батарея, аккумулятор и инвер- } \\
\text { тор }\end{array}$ \\
\hline J2 & $\begin{array}{l}\text { Приемник GPS и система наведения сол- } \\
\text { нечной панели на Солнце }\end{array}$ \\
\hline J3 & Модем \\
\hline J4 & Отладчик JTAC \\
\hline
\end{tabular}

Выводы микроконтроллера SAM4E (микросхема U4) сконфигурированы следующим образом: РВо, РВ1 - как входы АЦП, выводы РА23-PA27, PD18-PD27 - как выходы, предназначенные для управления механизмом поворота панелей, вывод РВ14 - как выход отладочного ЦАП, выводы РА9, РА10, РА21, РА22 - как два порта RS-232. Функции микросхем контроллера приведены в табл. 1, назначение разъемов - в табл. 2.

Поворот панелей является сложным динамическим процессом, и ему будет посвящена отдельная статья. Здесь же мы приводим фрагмент написанной на языке С программы управления агрегатами СЭУ, предназначенный для управления подключением нагрузки и отключением солнечных панелей от аккумуляторных батарей.

Для отладки программного обеспечения был изготовлен макет контроллера. Приведенная программа проверена и отлажена; алгоритмы и программы отладки будут рассмотрены в следующих публикациях.

\section{ЛИТЕРАТУРА}

1. Пчельникова-Гротова О. Проек-

тирование и расчет автономных фотоэлектрических энергетичесКИх установоК // ЭЛЕКТРОНИКА: Наука, Технология, Бизнес. 2019. № 1. С. 120-127.

2. Акулинин А., Смыков В. Оценка возможностей солнечной энергетики на основе точных наземных измерений солнечной радиации // Проблемы региональной энергетики. 2008. № 1 .
3. Пчельникова-Гротова О.Н., Мин М.Т. Оценка ресурсов солнечной энергии для снабжения наземных систем обеспечения полетов в республике Мьянма // Труды МАИ. 2016. № 91. http://trudymai.ru/published.php? ID=75619.

4. Интернет-ресурс http://mirvetra.com.ua/suntracker.html

5. Жаров В.Е. Сферическая астрономия. - Фрязино: Век 2, 2006.

6. Фалеев Д.С. Возобновляемые и ресурсосберегающие источники энергии. - Хабаровск: Издательство ДВГУПС, 2005.

7. Solar Position Algorithm (SPA) Электронный ресурс https://midcdmz.nrel.gov/spa/.

8. чукан Й., костиков К. Тензометрические датчики силы // Компоненты и технологии. 2010. № 1. С. 16-18.

9. ADSP-21990: Implementation of PI Controllers. Analog Devices Inc., December, 2001.

https://www.analog.com / media / en / technicaldocumentation / application-notes / PI_ctrl.pdf g_afec_sample_data.value $=$ "cntr_data;//real level from from channel A ADC switch(batt_levl)

\{

case $1: / /$ if the battery is not charged

if (g_afec_sample_data.value < 1300)

\{

ievel(LED1 GPIO, 0 ):

ioport_set_pin_level(LED2_CPI0, 1);

batt_levl = 1 ;

\}

else

ioport_set_pin_level(LED1_GPI0,1);//the battery is charged

ioport_set_pin_level(LED2_GPI0,1)

batt_levl $=2$;

\}

break:

case $2: / /$ battery in normal

if (g_afec_sample_data.value < 1200)//check that the battery is in the village

ioport_set_pin_level(LED1_CPIO,0)

ioport_set_pin_level(LED1_CPIO,1)

batt_levl = 1;

\}

if(g_afec_sample_data.value > 1600)//check that the battery has a very high level of charge

\{

ioport_set_pin_level(LED2_GPIO,0);

ioport_set_pin_level(LED1_GPI0,1)

batt_levl = 3;

break;

case $3: / /$ the battery has a very high level of charge

if (g afec sample data value < 1500)//transition to normal mode \{

ioport_set_pin_level(LED1_CPI0,1)

ioport_set_pin_level(LED2_GPI0,1)

batt_levl = 2;

\}

\{

ioport_set_pin_level(LED2_CPIO,0);

batt_levl = 3 ;

\}

break;

default:

batt levl $=1$

\} 